\title{
New Hybrid Technique for Impulsive Noise Suppression in OFDM Systems
}

\author{
ALINA MIRZA*, AYESHA ZEB*, AND SHAHZAD AMIN SHEIKH* \\ RECEIVED ON 22.02.2016 ACCEPTED ON 16.08.2016 \\ ABSTRACT
}

\begin{abstract}
In this paper, a new hybrid technique employing RS (Reed Solomon) coding and adaptive filter for impulsive noise suppression in OFDM (Orthogonal Frequency Division Multiplexing) systems is presented. Adaptive filter creates a more accurate estimate of the original OFDM signal after impulsive noise cancellation. The residual impulsive noise is further mitigated by RS decoder in the second stage of proposed technique. Three members of adaptive filters family i.e. NLMS (Normalized Least Mean Square) algorithm, RLS (Recursive Least Square) algorithm and Bhagyashri algorithm are tested with RS decoder in the proposed hybrid technique. Furthermore, the results in terms of steady state MSE (Mean Square Error) reduction, BER (Bit Error Rate) improvement and SNR (Signal to Noise Ratio) enhancement confirm the effectiveness of the proposed dual faceted technique when compared with the recently reported techniques in literature.
\end{abstract}

Key Words: Orthogonal Frequency Division Multiplexing, Impulsive Noise, Reed Solomon Codes, Adaptive Algorithm, Bit Error Rate.

\section{INTRODUCTION}

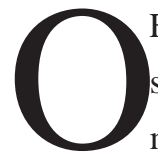

FDM is a variation of signal modulation that splits high data rate stream into numerous moderate balanced narrowband firmly divided subcarriers and is less delicate to frequencyselective fading. Therefore, OFDM has attracted much attention in past decades and is successfully implemented in the wired systems including DSL (Digital Subscriber Lines) [1], power line communications [2] and cellular communication standards like LTE/LTE-A and WiMAX [3].

OFDM systems are usually corrupted by impulsive noise, which is non-Gaussian in nature and has disastrous effect in OFDM transmission. The performance of OFDM systems is degraded due to the existence of impulsive noise in the received signal because of its wide frequency content [4]. Researchers are investigating solutions for mitigating this type of noise and to improve system performance. Different techniques are addressed in literature that endeavors to suppress impulsive noise from the original transmitted signal.

The conventional technique for impulsive noise suppression is median filter with some signal degradation [5]. The simplest time domain approaches like clipping

*Department of Electrical Engineering, College of Electrical \& Mechanical Engineering, National University of Sciences \& Technology, Rawalpindi.

Mehran University Research Journal of Engineering \& Technology, Volume 36, No. 3, July, 2017 [p-ISSN: 0254-7821, e-ISSN: 2413-7219] 
$[6,7]$ and nulling [8] are used to mitigate impulsive noise effect by removing the received OFDM signal peaks above certain threshold values. The BER characteristic of OFDM systems is further enhanced by the combination of clipping and nulling as presented in [9]. However, the techniques proposed in [6-9] cut off many noise samples after thresholding and as a result BER of OFDM systems is degraded. Therefore, Hirakawa et. al. [10] presented another sample replacement scheme for suppressing multiple impulses from the received OFDM signal. When the additional point of impulsive noise is a center point between OFDM samples in time domain, the performance of replacing sample scheme is degraded. This problem is solved by replica signal subtraction scheme [11], but it cannot reduce the influence of impulsive noise under the existence of multiple impulse events for class A noise. Two more schemes, replica signal [12] and iterative replica signal [13], are reported to solve the underline problem and improve the OFDM systems performance. The frequency domain technique for impulsive noise suppression is presented by Zhidkov, [14].Further, impulsive noise characteristics are exploited in both time and frequency domain in Al-Mawali et. al. [15] i.e.impulsive noise is cancelled in time domain, information signal detected in frequency domain and detected signal is trans formed back to time domain start next iteration. Liu et. al. [16] presented another iterative impulsive noise location and value search algorithm, which is based on exploiting the important relationship between impulsive noise and symbol constellation.

Due to their capability to track time variants of signal statistics in non-stationary environment, adaptive filters is the best solution for impulsive noise suppression [17]. Researchers opted LMS (Least Mean Square) filters in OFDM based power line communication systems in [18], for suppression of periodic impulsive noise. The NLMS, RLS, VSNLMS adaptive filters based receiver techniques for minimizing impulsive noise effect on OFDM systems performance under AWGN (Additive White Gaussian Noise) [19,20] and Rayleigh fading channel [21] are used. Khedkarand Murugan [22] also improved the OFDM systems performance by suppressing the inter carrier symbols effect using trained LMS adaptive filter based technique.

FEC (Forward Error Correction) codes are also used for mitigation of impulsive noise in literature [23-24]. The basic principle of FEC is based on introducing redundancies to the information to be transmitted. RS codes are used in reversible steganography on OFDM channel for securing data in wireless communication by Praveen et. al. [25].Researchers presented an impulsive noise reduction method by combining iterative impulsive noise cancellation along with space time block codes [26]. Another hybrid technique comprising of clipping and adaptive filter is implemented by Mirza et. al. [27] for impulsive noise removal. Jia et. al. [28-29] presented hybrid scheme based on time domain pre-processing mean filter i.e. CCV (Composite Comparison Value) in combination with RS coding in OFDM and ZigBee communication link that detects the location of an impulse and then subtracts it from the original noisy signal. Motivated by the idea of researchers in [26-29], a new hybrid technique for impulsive noise mitigation is presented in this research paper. In our proposed hybrid technique for impulsive noise suppression, we have used RS codes along with adaptive filters. Adaptive filter is being used to give an estimate of the impulsive noise which has the ability to adapt itself according to the environment by updating its filter coefficients. The aim of this research is to improve performance of OFDM systems by mitigating impulsive noise along with AWGN. In contrast with existing impulsive noise removal methods, proposed hybrid RSRLS technique delivers good resistance to impulsive noise as well as enhanced performance in terms of BER and SNR. 
The structure of paper is as: Section 2 presents the problem formulation and overview of system model, while Section 3 elaborates the proposed dual faceted technique which is followed by comparative analysis supported with the simulation results in Section 4. In the end, Section 5 concludes the paper and is then followed by the references.

\section{PROBLEM FORMULATION AND OFDM SYSTEM DESCRIPTION}

\subsection{Impulsive Noise}

Impulsive noise is a manmade noise that occur due to electrical cables, overwhelming current switches, vehicle ignition frameworks, high voltage release and different sources which cannot be thought to be considered as Gaussian in nature [5]. Unlike AWGN, impulsive noise has very high instantaneous power and wide frequency spectrum leading to high bit error rate and prevents receiver from correcting and deciding on transmitted symbols. Impulsive noise can be broadly divided into twotypes-aperiodicimpulsivenoiseandperiodicimpulsive noise. Periodic impulsive noise consists of impulses of long duration and occurs periodically in time. Aperiodic (or asynchronous) impulsive noise is characterized by impulses occurring at random times with short duration and high power. In this paper, we focused on aperiodic impulsive noise. There are three widely used statistical models for modeling aperiodic impulsive noise reported in literature i.e. Gaussian mixture [30], Middleton's ClassA [31] and Symmetric Alpha Stable models [32-33]. We focused on the Gaussian mixture model and assumed the impulsive noise to be Poisson Gaussian, where amplitude is modeled by Gaussian distribution and rate of occurrence of impulses is modeled by Poisson distribution and expressed as:

$\mathrm{n}_{\mathrm{i}}(\mathrm{l})=\mathrm{p}(\mathrm{l}) \mathrm{n}(\mathrm{l}) \quad \mathrm{l}=0,1 \ldots \mathrm{N}-1$
Where $\mathrm{p}(\mathrm{l})$ is binary Poisson process of random sequence of ones and zeros, and $\mathrm{n}(\mathrm{l})$ is random noise process. In Poisson-Gaussian model, the probability density functions of impulsive noise in small time interval of $\Delta \mathrm{x}$ is given by:

$f_{N}^{P G}\left(n_{i}(l)\right)=(1-\lambda \Delta x) \delta\left(n_{i}(l)\right)+\lambda \Delta x f_{N}\left(n_{i}(l)\right)$

Where $\mathrm{f}_{\mathrm{N}}$ is the Gaussian pdf. The amplitudes of impulsive noise are calculated by the following Gaussian pdf.

$f_{N}(n(l))=\frac{1}{\sqrt{2 \pi \sigma}} e^{\left[\frac{-n^{2}(l)}{2 \sigma^{2}}\right]}$

\section{$2.2 \quad$ OFDM Model}

OFDM is a variant of signal modulation that splits the modulated high data rate stream into many slow modulated narrow band closely spaced subcarriers and is less sensitive to frequency selective fading. The basic OFDM system is given in Fig. 1.

FFT (Fast Fourier Transform) and IFFT (Inverse Fast Fourier Transform) blocks are used in OFDM systems for efficient implementation. The input data bits are modulated into symbols, passed through the serial to parallel block and converted into parallel format. The IFFT block manages the subcarriers and orthogonality among them. The symbols are modulated on different subcarriers and the signal is converted into time domain by IFFT block. Guard interval is added to avoid ISI (InterSymbol Interference) byusing cyclicredundancy which involves copying end portion of symbol and appending it to the start. This OFDM signal alongwith guard intervalis transmitted through channel. The transmitted OFDM signal is perturbed by impulsive and white Gaussian noise by channel. At the receiver end, the removal ofcyclic redundancyis carriedout, which is followed byFFT block. After that the signal is demodulated and original signal is retrieved. 


\section{PROPOSED HYBRID TECHNIQUE}

The schematic of the proposed hybrid technique employed in OFDM systems for impulsive noise mitigation is shown in Fig. 2. RS error correction scheme is used in combination with adaptive filters as a dual protection strategy. RS code can remove the burst errors but RS decoder error correction capability fails in presence of large impulsive noise. To avoid such situation, at the receiver side adaptive filter is applied before RS decoder for minimizing the impulsive noise effects from OFDM signal.

\subsection{Application of Adaptive Filter as Noise Canceller}

In this research, we have used adaptive noise canceller for suppression of impulsive noise. Among the family of adaptive algorithms, NLMS algorithm, Bhagyashri algorithm and RLS algorithm is used.

An ANC (Adaptive Noise Canceller) with two primary and reference inputs is shown in Fig. 3. The signal source generates the primary input $\mathrm{s}(\mathrm{n})$ which is corrupted by

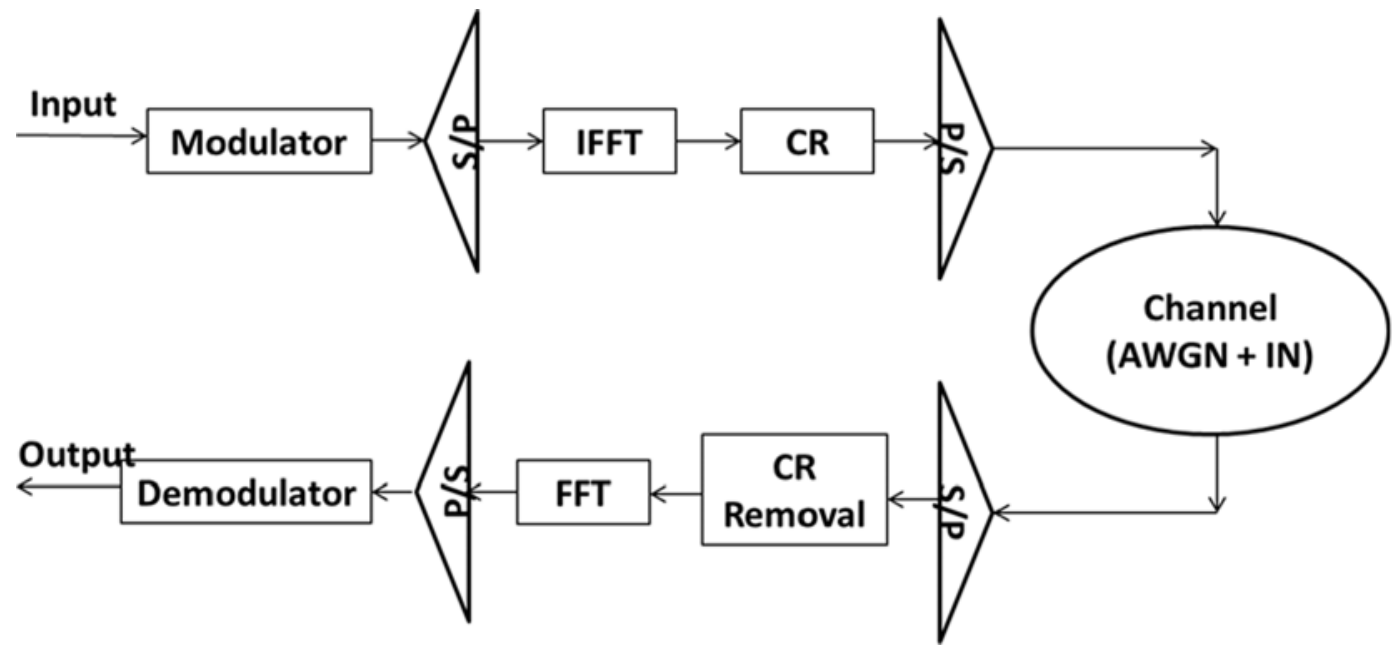

FIG. 1. BLOCK DIAGRAM OF OFDM SYSTEM

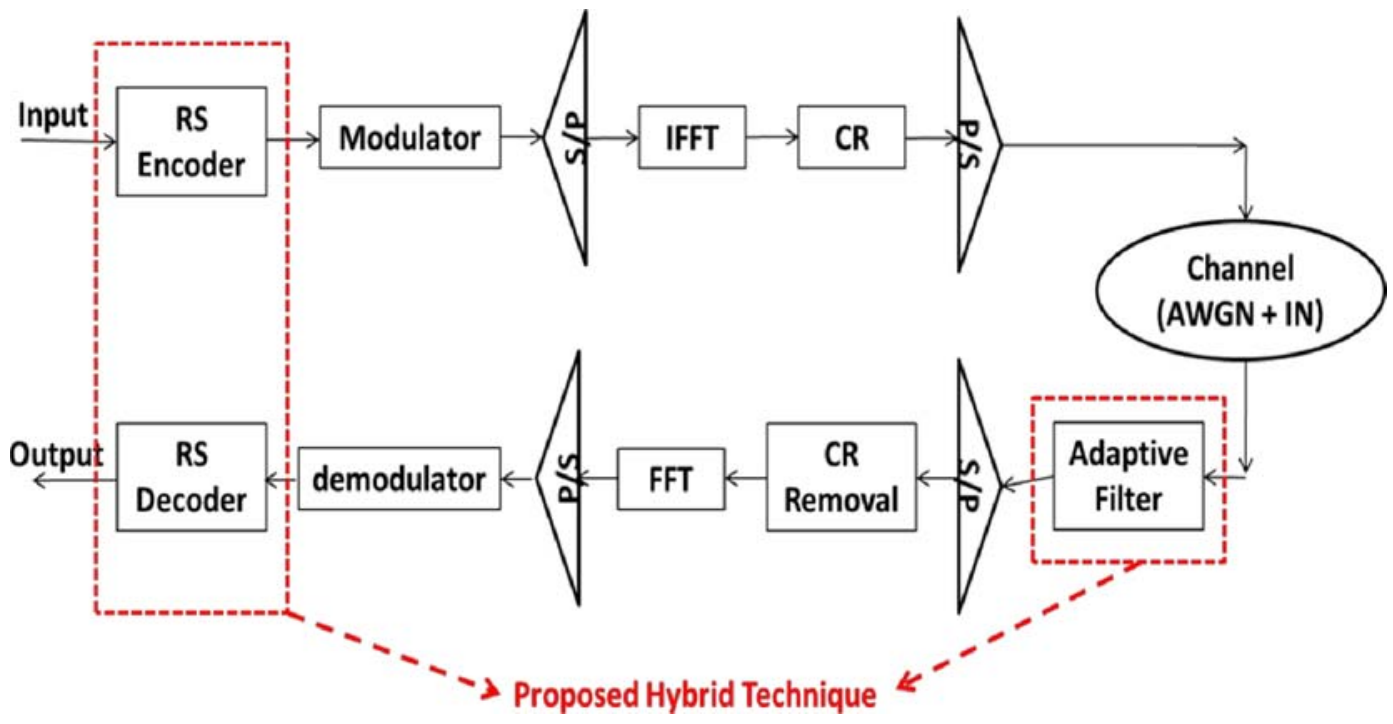

FIG. 2. SCHEMATICS OF PROPOSED TECHNIQUE 
noise $n(n)$. The noise $n_{0}(n)$ received by reference inputis uncorrelated with the signal s(n) but correlated in some way with the noise $n(n)$ [33]. The adaptive filter produces an output $\hat{n}(n)$ that is a close estimate of $n(n)$ present in primary input. This noise is subtracted from the received noisy signal $r(n)$ to produce an estimate; of the signal $\hat{s}(n)$ at the output of ANC system.

$e(n)=r(n)-\widehat{n}(n)=s(n)+n(n)-\widehat{n}(n)=\widehat{s}(n)$
Thus the system error signal e(n) should contain the original signal s(n) in an optimum sense. The adaptive filter output $\hat{n}(n)$ is given by:

$\hat{n}(n)=w^{T}(n) n_{0}(n)$

where $\mathrm{w}(\mathrm{n})$ is $\left[\mathrm{w}_{0}(\mathrm{n}), \mathrm{w}_{1}(\mathrm{n}), \ldots \ldots \mathrm{w}_{\mathrm{M}-1}(\mathrm{n})\right]$ is adaptive filter tap weights. The adaptive algorithm recursively updates the vector of tap weights.

The weight update equations of investigated adaptive algorithms are given in Table 1.

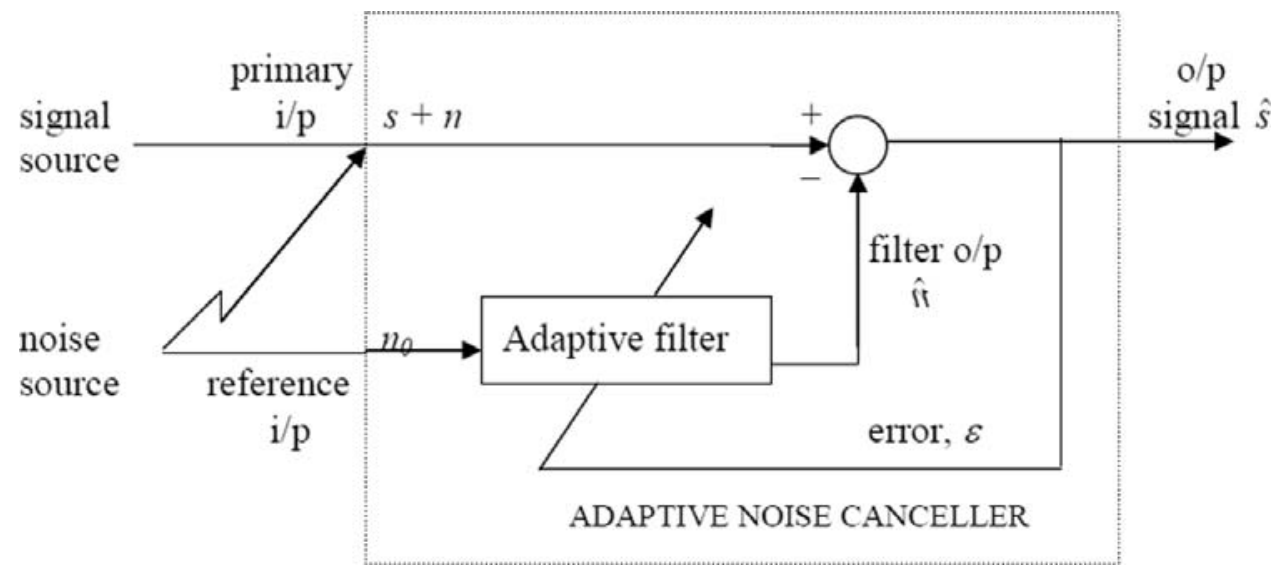

FIG. 3. ADAPTIVE FILTER NOISE CANCELLATION CONFIGURATION

TABLE 1. SUMMARY OF INVESTIGATED ADAPTIVE ALGORITHMS

\begin{tabular}{|c|c|c|}
\hline Adaptive Algorithm & Weight Update Equation & Step Size/Gain update Equation \\
\hline NLMS & $w(n+1)=w(n)+\mu(n) e(n) n_{o}(n)$ & $\mu(n)=\frac{\mu}{\left|n_{0}(n)^{2}\right|+\delta}$ \\
\hline Bhagyashri & $w(n+1)=w(n)+\mu \cdot \tanh [\beta \beta \cdot e(n)$ & 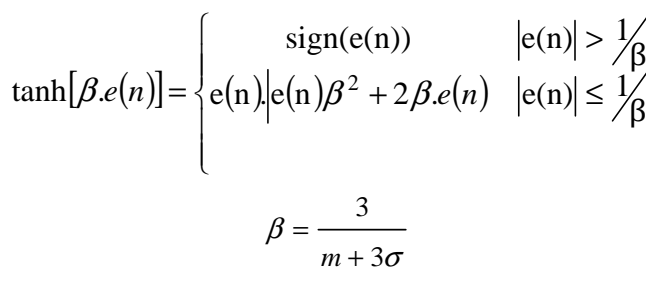 \\
\hline RLS & $\mathrm{w}(\mathrm{n}+1)=\mathrm{w}(\mathrm{n})+\mathrm{k}(\mathrm{n}) \mathrm{n}_{0}(\mathrm{n})$ & $\begin{array}{c}k(n)=\frac{\lambda^{-1} \phi^{-1}(n-1) n_{0}(n)}{1+\lambda^{-1} n_{0}(n)^{T} \phi^{-1}(n-1) n_{0}(n)} \\
\phi^{-1}(n)=\lambda^{-1} \phi^{-1}(n-1)-\lambda^{-1} k(n) n_{0}(n)^{T} \phi^{-1}(n-1)\end{array}$ \\
\hline
\end{tabular}

Mehran University Research Journal of Engineering \& Technology, Volume 36, No. 3, July, 2017 [p-ISSN: 0254-7821, e-ISSN: 2413-7219] 
Table 2 briefly describes the variables used in the investigated algorithms.

\subsection{Application of Reed Solomon Decoding Process}

The remaining impulsive noise and additive white Gaussian noise from the received OFDM signal will be removed by the second step of the proposed scheme i.e. the RS decoder, which is applied after the demodulation block. RS decoder is used to remove the burst errors because it replaces the whole by their respective of the number of bits in error [34]. The bit RS codes (v,t), where tis number of data symbols, vis number of code; symbols for all coding block, that is $\left.(\mathrm{v}, \mathrm{t})=2^{\mathrm{b}}-1,2^{\mathrm{b}}-2 \mathrm{k}-1\right)$, where $\mathrm{k}$ is the length of error correcting capability and $2 \mathrm{k}$ is the length of parity symbol. The syndrome computation is the parity check performed on output of FFT block in OFDM system, in order to remove error produced by noise. It is calculated as:

$s \hat{y}=\hat{R} \hat{H}^{T}=(\hat{C}+\hat{E}) \hat{H}^{T}=\hat{E} \hat{H}^{T}=s \hat{y}_{1}, s \hat{y}_{2} \ldots \ldots . s \hat{y}_{v-t}$

The received code word is $\hat{R}, \hat{C}$ is the original; transmitted; code; word, the error; vector is $\hat{E}=\hat{e}_{1}, \hat{e}_{2} \ldots \ldots \hat{e}_{v}$ and $\hat{H}^{T}$ is the parity check matrix transpose. The syndrome is dependent on error, not on

TABLE 2. DETAIL OF PARAMETERS FOR PROPOSED TECHNIQUE

\begin{tabular}{|c|c|}
\hline Variables & Description \\
\hline$\mu$ & Step size of NLMS algorithm \\
\hline$\mu(n)$ & Time varying normalized step size \\
\hline $\mathrm{e}(\mathrm{n})$ & Error signal \\
\hline$\beta$ & $\begin{array}{l}\text { Concavity control in the cost function of Bhagyashri } \\
\text { algorithm }\end{array}$ \\
\hline M & Mean of error signal \\
\hline$\sigma$ & Standard deviation of error signal \\
\hline K & Gain of RLS algorithm \\
\hline$\phi(n)$ & Cross correlation matrix \\
\hline$\lambda$ & Forgetting factor of RLS algorithm \\
\hline
\end{tabular}

the transmitted code word. Let's assume that there are perrors in the code word at locations $\mathrm{M}^{\mathrm{f} 1}, \mathrm{M}^{\mathrm{f} 2}, \ldots \mathrm{M}^{\mathrm{fp}}$ with; error; values $Z_{f 1}, Z_{f 2} \ldots Z_{f p}$ where indices $1,2, \ldots$ prefer to the error numbers and $f$ represents error location. The error polynomial can be represented as:

$$
\hat{E}(i)=Z_{f_{1}} M^{f_{1}}+Z_{f_{2}} M^{f_{2}}+\ldots . Z_{f_{p}} M^{f p}
$$

Each location $\mathrm{M}^{\mathrm{fa}}$ and its error value $\mathrm{Z}_{\mathrm{fa}}$ is determined by finding the error location defined by $\psi_{\mathrm{a}}=\alpha^{\mathrm{fa}}$, here $\alpha$ represents Galois field elements. Next, $\alpha^{\text {fa }}$ is passed to the received polynomial, with c ranges from 1-2p. Further, syndrome symbols are calculated as:

$s y_{c}=\sum Z_{f_{a}} \psi_{a}^{c}$

For finding the error values $\mathrm{Z}_{\mathrm{fa}}$, and locations $\mathrm{M}^{\mathrm{fa}}$, the polynomial for error; location $\zeta(\mathrm{i})$; is:

$$
\zeta(i)=\prod_{a=1}^{k}\left(1-\psi_{a} i\right)=\zeta_{k} i^{k}+\zeta_{k-1} i^{k-1}+\zeta_{1} i+\zeta_{0}
$$

In Equation (9), 1/ $\psi_{\mathrm{a}}$ represents roots and $\psi_{\mathrm{a}}$ are locations of error. The BM (Berlekamp; Massey) iterative method is employed to find syndrome polynomial $s_{y}$.

$$
\begin{aligned}
& s \hat{y}(i)=1+s \hat{y}_{1} i^{1}+s \hat{y}_{2} i^{2} \ldots \ldots . s \hat{y}_{2 k} i^{2 k} \\
& z(i)=s \hat{y}(i) \zeta(i)=1+\left(s \hat{y}_{1}+\zeta_{1}\right) i+\left(s \hat{y}_{2}+s \hat{y}_{1} \zeta_{1}+2 \zeta_{2}\right) i^{2}+. \\
& \left.\ldots \ldots \ldots \ldots\left(s \hat{y}_{k}+\zeta_{1}+s \hat{y}_{k-2}+\zeta_{2} \ldots \ldots+\zeta_{0}\right) i^{k}\right) \\
& =1+z_{1} i+z_{2} i^{2}+\ldots \ldots . . z_{k} i^{k}
\end{aligned}
$$

For the BM iterative processing, a step difference function $\mathrm{b}_{1}$ is calculated by:

$$
s \hat{y}(i) \zeta^{l}(i)=z^{l}(i) b_{l} i^{l+1}\left(\operatorname{modi} l^{l+2}\right)
$$

In Equation (11), 1 is the $\mathrm{l}^{\text {th }}$ iteration and b, $\zeta(\mathrm{i}), \mathrm{z}(\mathrm{i})$ are calculated as:

$$
b_{l}=s \hat{y}_{l+1}+\sum_{c=1}^{\partial z^{l}(i)} s \hat{y}_{l+1-c} z_{c}^{(l)}
$$


$z^{l+1}(i)=\left\{\begin{array}{cc}\zeta^{l+1}(i)=\zeta^{l}(i)+b_{l} b_{j}^{-1} i^{1-j} \zeta^{1}(i) & b_{l} \neq 0 \\ \zeta^{1}(i) & b_{l}=0\end{array}\right.$

The roots in Equation (9) are found by the Chien-search algorithm and the error location polynomial after $2 \mathrm{k}$ iterations,

$\zeta(\mathrm{i})=\zeta^{2 \mathrm{k}}(\mathrm{i})$

The Forney algorithm is used to find error value and is given as:

$M_{f_{1}}=-\frac{z\left(\psi_{1}^{-1}\right)}{\zeta\left(\psi_{1}^{-1}\right)}$

Decoding with error correction is done when the error polynomial is obtained.

\subsection{Pseudo Code of Proposed Hybrid Technique}

The summarized algorithm for proposed technique for OFDM systems is shown in Fig. 4.

Here $\mathrm{x}(\mathrm{n})$ is system input, $\mathrm{s}(\mathrm{n})$ is OFDM signal, $\mathrm{r}(\mathrm{n})$ is noisy OFDM, $\overline{\mathrm{r}}(\mathrm{n})$ is output of adaptive filter, and $\hat{\mathrm{y}}(\mathrm{n})$ is system output

\section{Initial Values:}

$\mathrm{b}=0$

$r^{(0)}=r$

\section{SIMULATION RESULTS}

OFDM system affected by impulsive noise is implemented using the MATLAB platform. The performance of proposed hybrid technique is compared with those of already reported techniques in literature $[27,28]$ in both AWGN and Rician channel. The parameters used in simulating the OFDM system are described in Table 3.
The binary random data is generated and passed to the RS encoder. After encoding and modulation, the signal is transmitted by OFDM transmitter which is illustrated in Fig. 5.

This OFDM signal is then propagated from the channel containing AWGN and impulsive noise. The impulsive noise is generated by the algorithm mentioned in [36] and illustrated in Fig. 6(a-b).

The histogram of the generated impulsive noise shows that noise pulses with amplitude less than 0.75 have very

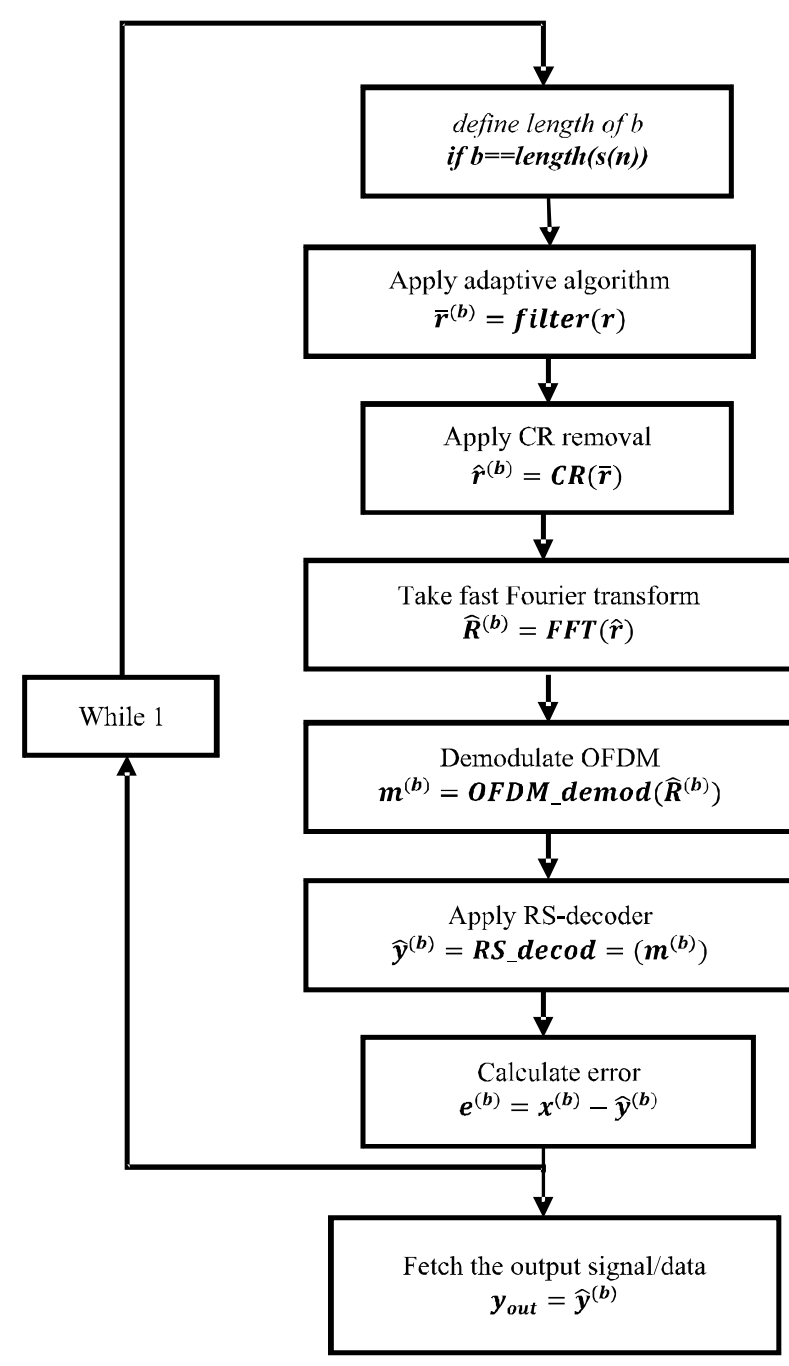

FIG. 4. ALGORITHM FOR PROPOSED TECHNIQUE FOR OFDM SYSTEMS

Mehran University Research Journal of Engineering \& Technology, Volume 36, No. 3, July, 2017 [p-ISSN: 0254-7821, e-ISSN: 2413-7219] 
high rate of occurrence as compared to the pulses that have amplitude from 0.75-1. However, the high peaked impulses with amplitude between 1.5-2.5 occur rarely. When the OFDM signal propagates through the channel containing AWGN and impulsive noise, it gets perturbed. The noisy OFDM signal is shown in Fig. 7.

This noisy received signal is filtered through an adaptive filter and then OFDM receiver operates in reverse order for sorting encoded symbols in original sequence. After demodulation RS decoder is applied for further reducing the impact of noise from the perturbed signal. The performance of NLMS, Bhagyashri and RLS filters in combination with RS code are compared in terms of BER. Extensive simulations are carried out to study the effect of step size on NLMS and Bhagyashri filters by varying different modulation schemes. These values are used as a guideline to tune the stepsize for the rest of the simulations. Fig. 8(a-f) shows the BER curves for varying step size of hybrid Algorithm (a-c) RS-NLMS and (d-f) RS-Bhagyashri in AWGN channel for BPSK, QPSK and 16QAM constellations respectively.

As both adaptive filters i.e. NLMS and Bhagyashri belong to two different adaptive filter families. The investigated step size range is kept different in Fig. 8 because both filters have a different convergence range. For understanding purpose, in Fig. 8, we have kept the investigated range of step sizes same (0.0001 to 0.1 ) for both proposed hybrid techniques. Fig. 9(a) shows RSBhagyashri while Fig. 9(b) showsRS-NLMS technique with varying step size and we can see that RS-Bhagyashri is not giving good convergence in this range. RSBhagyashri shows better convergence for smaller step size values (0.00001 to 0.001 ) as compared to the step size values of RS-NLMS as shown in Fig. 8.

RLS algorithm does not have step size parameter. In RLS, the controlling parameter is delta $(\delta)$. Moreover, $\delta$ is a critical parameter for convergence of the algorithm which is used in the initialization of RLS algorithm. The regularization parameter $\delta$ depends on SNR or in other

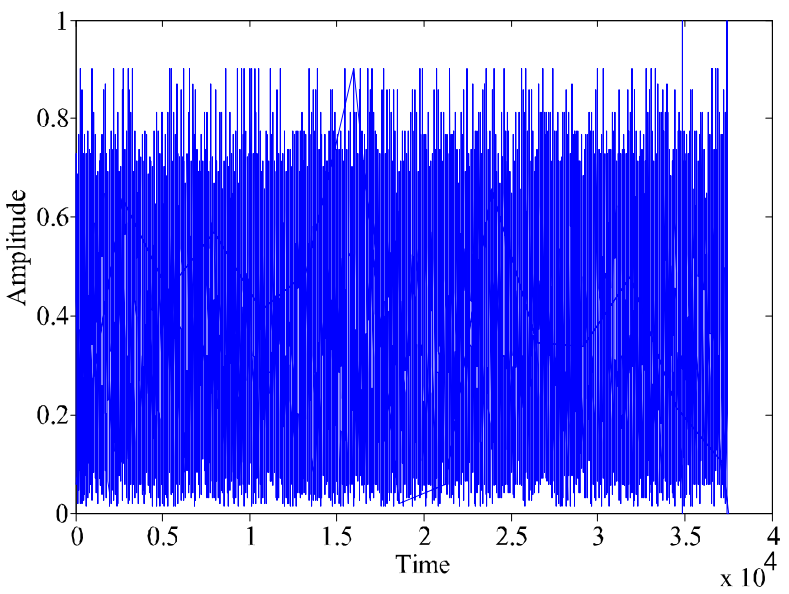

FIG. 5. TRANSMITTED OFDM SIGNAL

TABLE 3. SIMULATION PARAMETER SET FOR PROPOSED HYBRID TECHNIQUE

\begin{tabular}{|c|c|c|c|}
\hline \multicolumn{2}{|c|}{ OFDM System } & \multicolumn{2}{|c|}{ Impulsive Noise } \\
\hline Parameters & Values & Parameters & Value \\
\hline Modulation technique & QPSK & Sampling frequency & 8 \\
\hline Size of cyclic prefix & 2 & Total time & 4681 \\
\hline FFT-length & 8 & Samples intermediate average time & $1 \mathrm{~s}$ \\
\hline \multirow{4}{*}{ Number of bits generated } & \multirow{4}{*}{32767} & Log amplitude mean value & $3 \mathrm{~dB}$ \\
\hline & & Standard deviation of log amplitude & $2 \mathrm{~dB}$ \\
\hline & & Mean of AWGN & 0 \\
\hline & & Standard deviation of AWGN & 0.8 \\
\hline
\end{tabular}

Mehran University Research Journal of Engineering \& Technology, Volume 36, No. 3, July, 2017 [p-ISSN: 0254-7821, e-ISSN: 2413-7219] 
words, variance of the input signal $x^{\prime}(n)$ [17]. When the noise level in the tap inputs is low, the RLS algorithm exhibits high convergence rate, provided that $\delta$ is chosen small enough; whereas, if noise level is very high it is preferable to initialize the algorithm with large value of $\delta$ [17]. The effect of varying $\delta$, from very small value to quite large values (0.05 to 1000) for impulsive noise is shown in Fig. 10 (a-c) for BPSK, QPSK and 16QAM constellations respectively.

From these experiments, the optimum parameters selected for proposed hybrid technique are shown in Table 4.

On the basis of optimum parameters for the respective algorithms, the performance comparison between proposed hybrid RS-NLMS, RS-Bhagyashri and RS-RLS algorithms for AWGN channel is shown in Fig. 11(a-c).

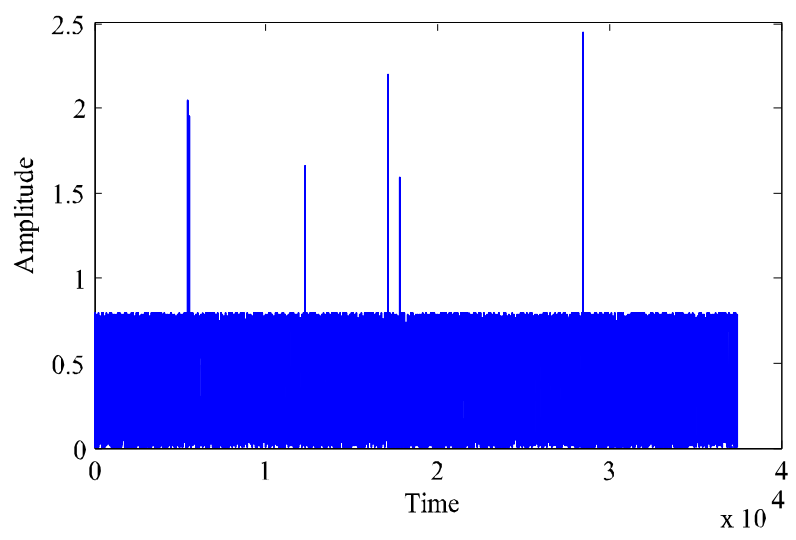

FIG. 5(a). TIME DOMAIN IMPULSIVE NOISE SIGNAL

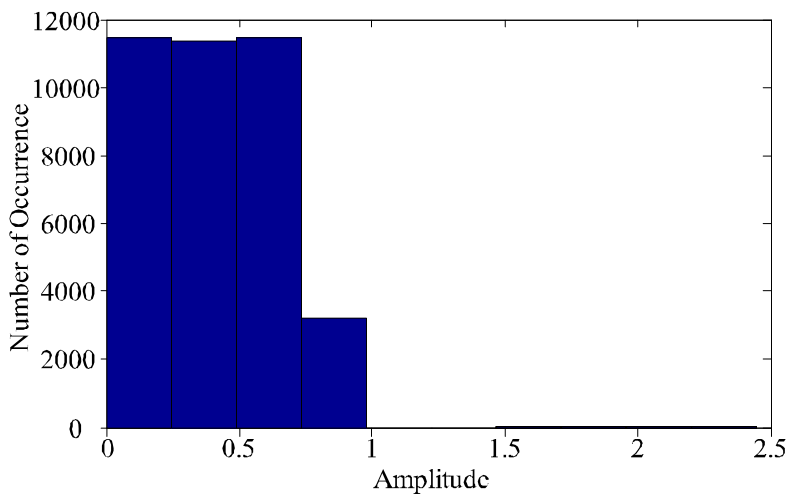

FIG. 6(b). HISTOGRAM OF GENERATED IMPULSIVE NOISE
It is important to note that RLS filter gives better BER performance than NLMS and Bhagyashri filter when used in our proposed hybrid technique for all the three modulations as depicted in Fig. 11.

Fig.12 shows MSE comparison of proposed hybrid techniques. We calculated MSE of proposed hybrid technique based on RS coding and adaptive filters i.e. NLMS, Bhagyashri and RLS filters because adaptive filters are based on a cost function i.e. minimization of error signal [37]. The error signal in adaptive filters is fed back to the weight update mechanism and the filter coefficients are adjusted accordingly. That is why MSE criterion is used to judge the performance of adaptive filters in proposed hybrid technique. While, MSE of RSCCV hybrid technique reported in [28] is not compared in Fig.11, because CCV is a fixed filter that is based on a windowing method and no error criteria is used in it. So, in order to do a fair comparison MSE of hybrid techniques based on adaptive filters only are compared in Fig. 12.

The MSE in $\mathrm{dB}$ simulation result also confirms that proposed hybrid RS-RLS gives lowest MSE and fastest convergence as compared to the proposed hybrid RSNLMS and proposed hybrid RS-Bhagyashri algorithms as depicted in Fig. 12. The mean square value of RS-RLS algorithm is $-14 \mathrm{~dB}$, whereas RS-Bhagyashri algorithm has MSE value less than $-2 \mathrm{~dB}$.

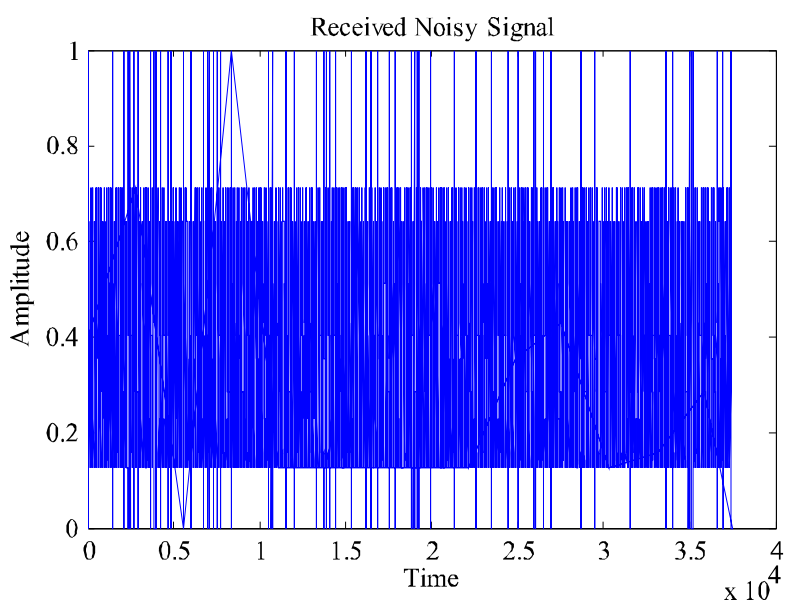

FIG.7. NOISY OFDM SIGNAL WITH AWGN AND IMPULSIVE NOISE 
The comparison of our proposed hybrid technique (RSRLS) with individual RS coding and RLS filtering is performed in Fig. 13 for suppressing impulsive noise in AWGN channel. In these results, the RLS filtering shows better performance when compared to RS coding alone However, significant BER improvement is achieved in our proposed dual faceted technique by combining RS error

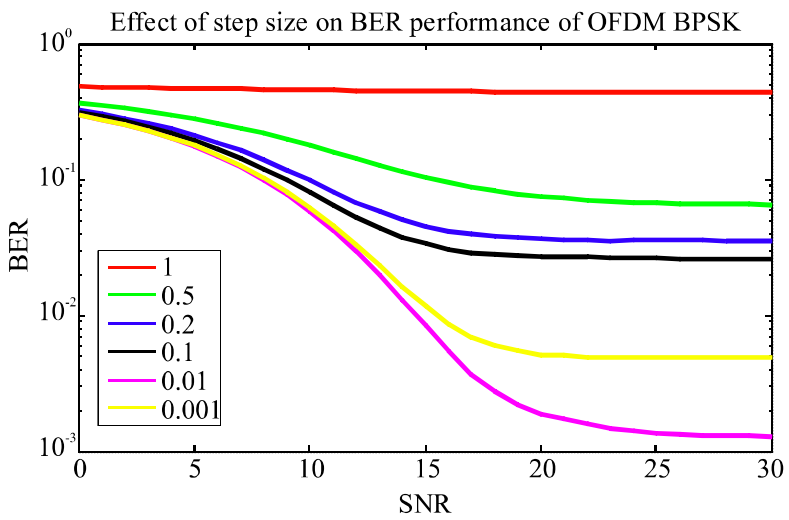

(a)RS-NLMS FOR BPSK

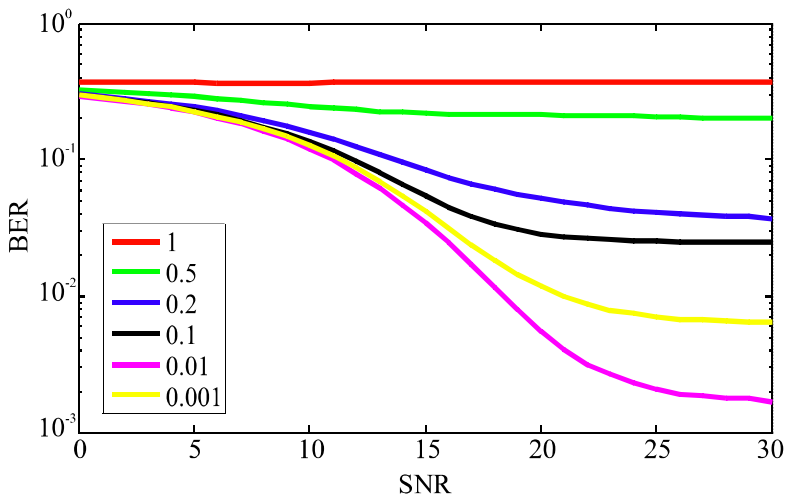

(b) RS-NLMS FOR QPSK

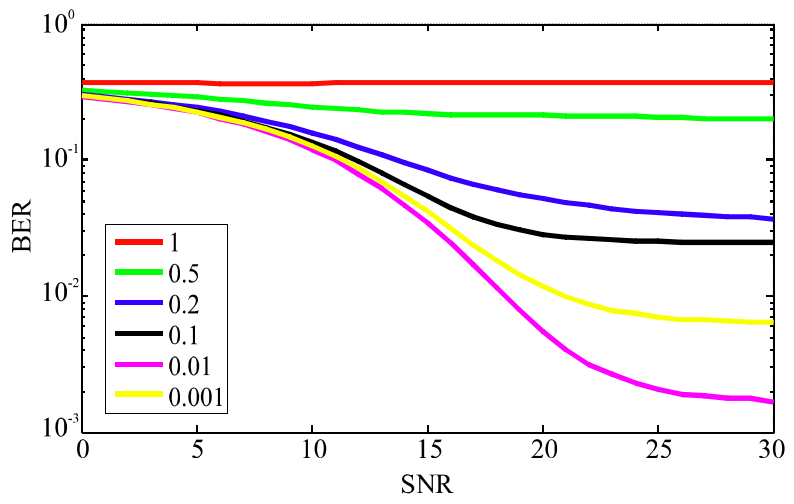

(c) RS-NLMS FOR 16QAM correction codes with RLS filter. Initially, RLS filter estimates the OFDM signal after suppressing impulsive noise and RS decoder removes the enduring impulsive noise in second step of proposed dual faceted technique. Moreover, the proposed hybrid technique out performs other hybrid techniques reported in literature $[27,28]$ in Fig. 13 for mitigation of impulsive noise.

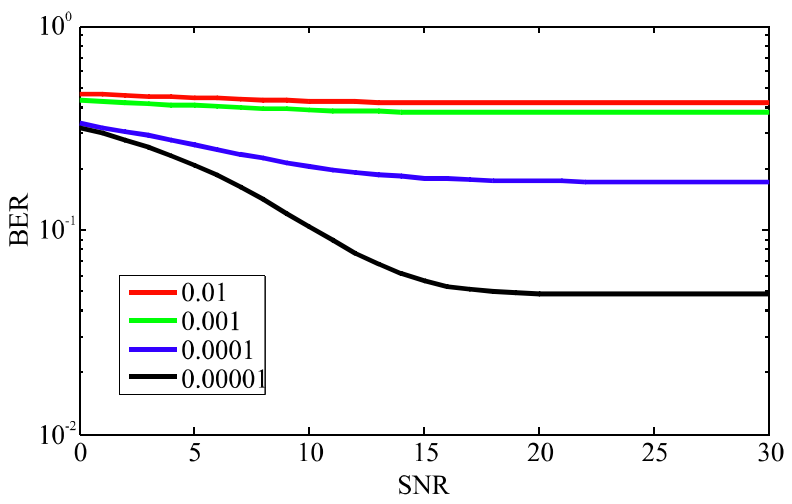

(d)RS-BHAGYASHRI FOR BPSK



(e) RS-BHAGYASHRI FORQPSK

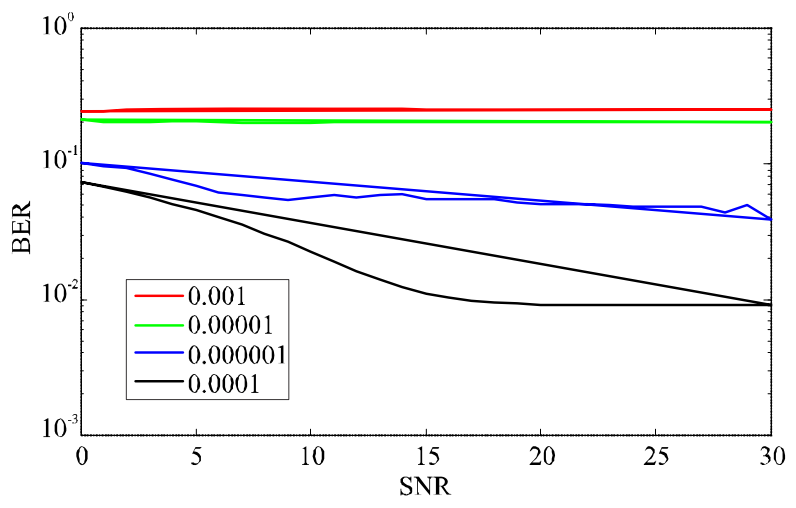

(f) RS-BHAGYASHRI FOR 16QAM

FIG. 8. BER CURVES WITH VARYING STEP SIZE OF PROPOSED HYBRID ALGORITHM 
The new proposed hybrid algorithms RS-NLMS, RSBhagyashri and RS-RLS are also compared in terms of SNR degradation in Table 5. From Table 5 that the hybrid RS-RLS technique produces minimum SNR degradation. This again verifies our claim that RS-RLS gives better performance for impulsive noise mitigation in OFDM systems than other variants. The SNR degradation is obtained by the difference of SNR of OFDM signal and filtered signal, where the maximum SNR of the OFDM signal is $4.512 \mathrm{~dB}$.

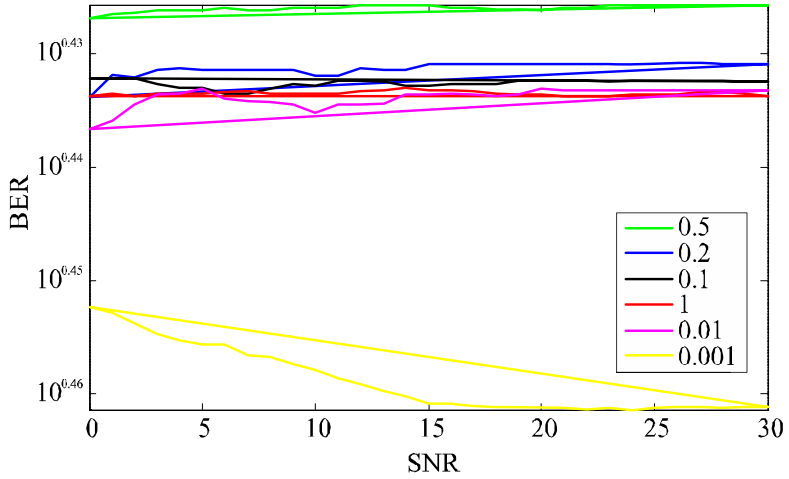

(a)

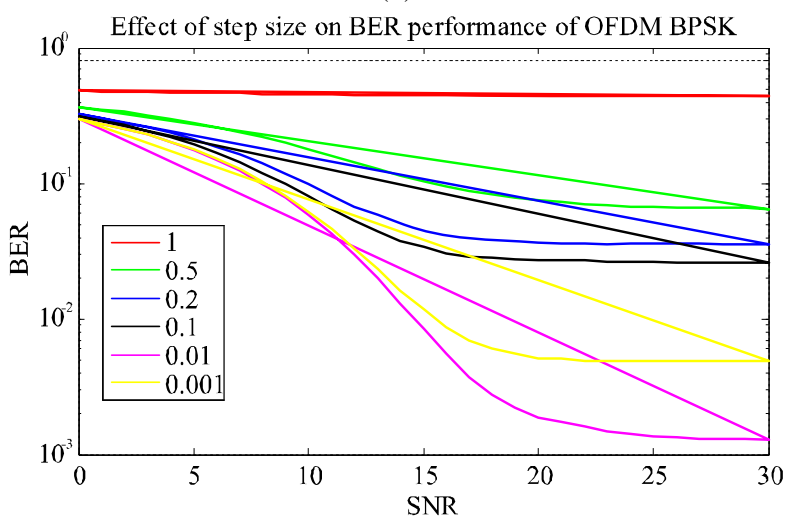

(b)

FIG. 9. EFFECT of VARYING STEP SIZE ON HYBRID RSBHAGYASHI ALGORITHM

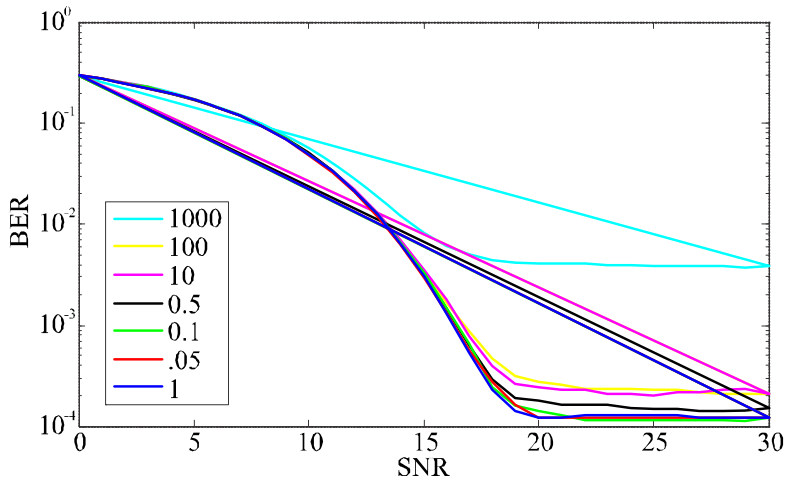

(a)

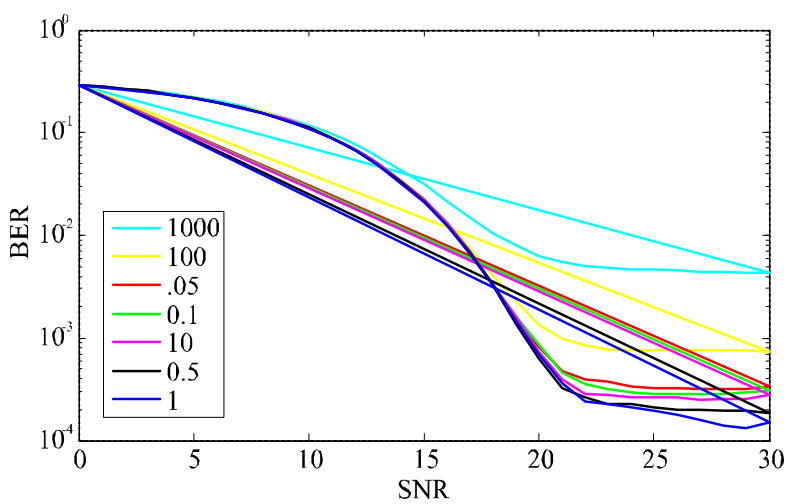

(b)

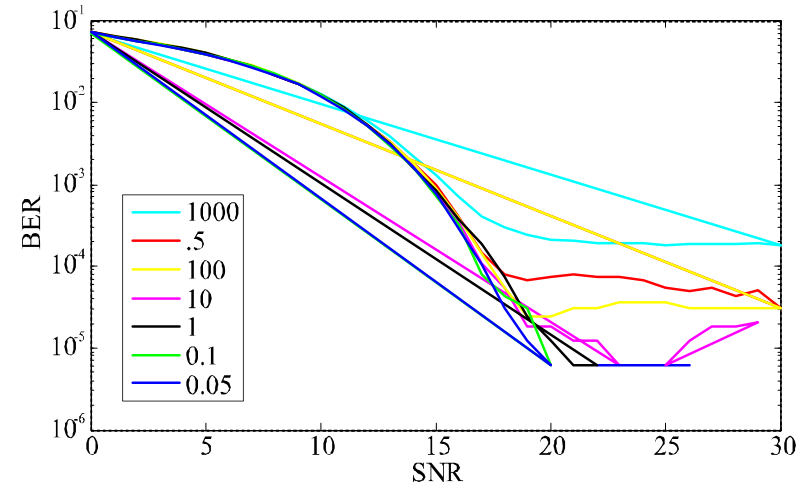

(c)

FIG. 10. EFFECT of VARYING DELTA ON HYBRID RS-RLS ALGORITHM FOR A) BPSK B) QPSK C) 16QAM

TABLE 4. OPTIMUM PARAMETERS FOR VARIANTS OF PROPOSED HYBRID TECHNIQUE

\begin{tabular}{|c|c|c|c|}
\hline Modulation & $\begin{array}{c}\text { RS-NLMS } \\
\text { (Stepsize Values) }\end{array}$ & $\begin{array}{c}\text { RS-Bhagyashri } \\
\text { (Stepsize Values) }\end{array}$ & $\begin{array}{c}\text { RS-RLS } \\
\text { (Delta Values) }\end{array}$ \\
\hline BPSK & 0.05 & 0.0001 & 1 \\
\hline QPSK & 0.01 & 0.0001 & 1 \\
\hline 16QAM & 0.01 & 0.0001 & 0.05 \\
\hline
\end{tabular}

Mehran University Research Journal of Engineering \& Technology, Volume 36, No. 3, July, 2017 [p-ISSN: 0254-7821, e-ISSN: 2413-7219] 


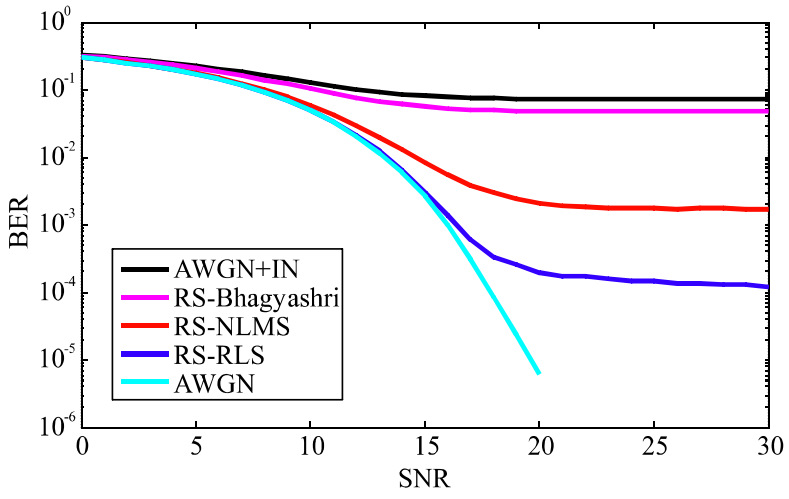

(a) BPSK

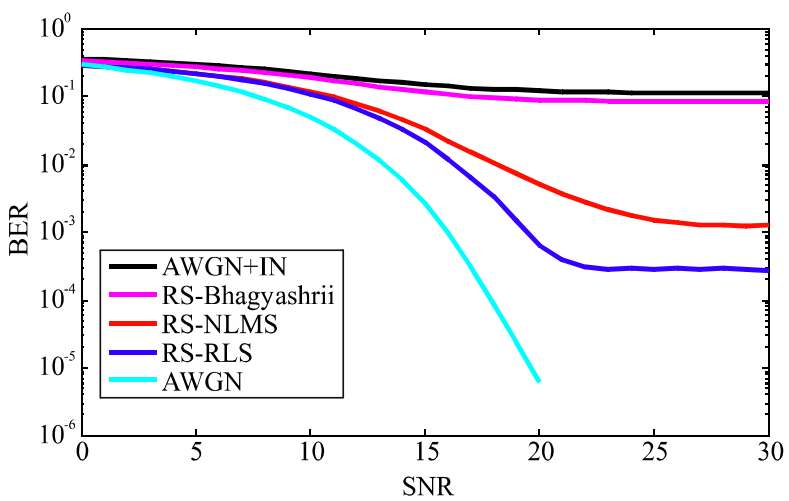

(b) QPSK

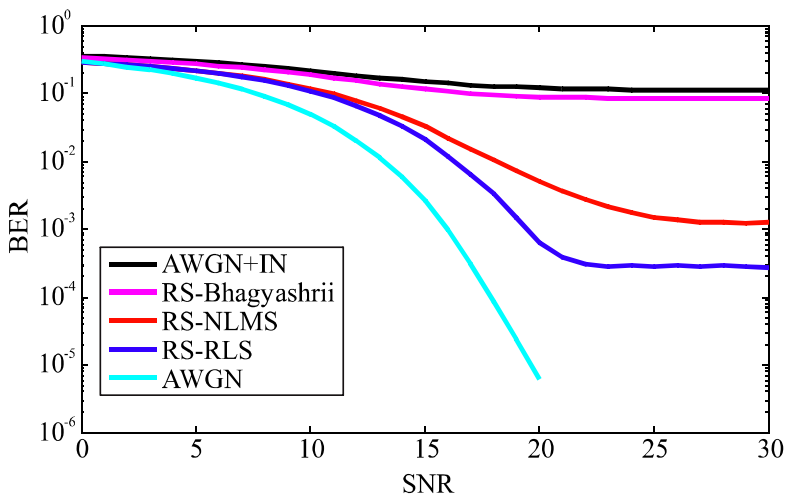

(c) 16QAM

FIG. 11. COMPARISON OF BER FOR PROPOSED HYBRID ALGORITHMS
The performance gain of proposed technique is also investigated for Rician fading channel. The transmitted signal reaches the receiver through different paths in Rician channel and exhibits multipath interference. The objective of this choice is to study the robustness of proposed dual faceted hybrid technique against changes in the environment. Fig. 14 shows BER comparison of variants of our proposed hybrid technique in Rician

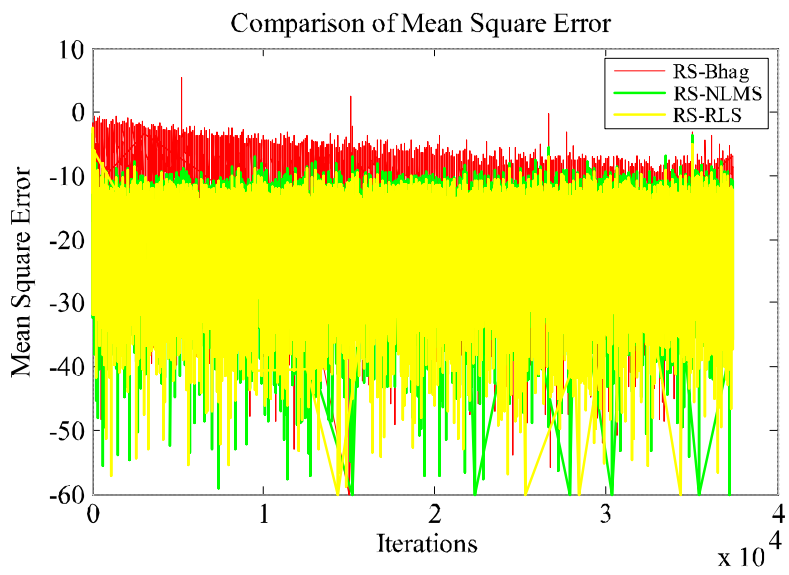

FIG. 12. COMPARISON OF MSE FOR PROPOSED HYBRID RS-NLMS, RS-BHAGYASHRI AND RS-RLS ALGORITHMS

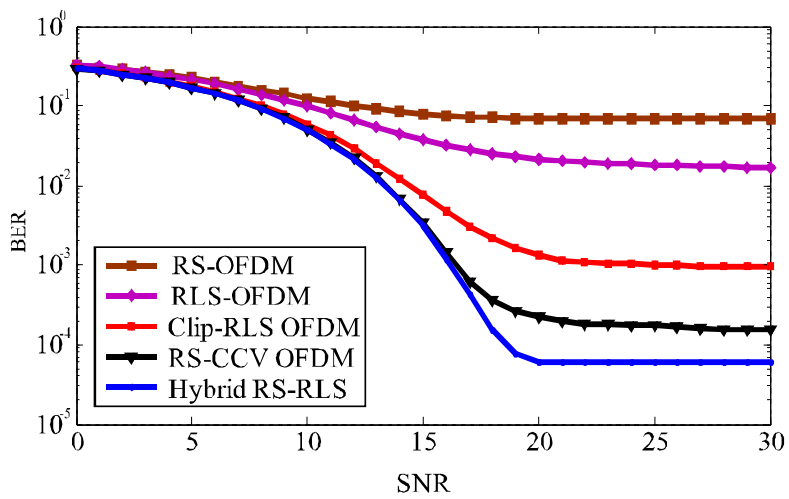

FIG. 13. BER COMPARISON OF PROPOSED HYBRID TECHNIQUE EMPLOYED IN OFDM SYSTEM

TABLE 5. SNR COMPARISON OF PROPOSED TECHNIQUES

\begin{tabular}{|c|c|c|c|}
\hline Algorithms & Maximum Signal SNR & Filtered Signal SNR & SNR Degradation (dB) \\
\hline RS-NLMS & 4.512 & 3.8069 & 0.7051 \\
\hline RS-Bhagyashri & 4.512 & 0.27 & 4.242 \\
\hline RS-RLS & 4.512 & 3.966 & 0.546 \\
\hline
\end{tabular}

Mehran University Research Journal of Engineering \& Technology, Volume 36, No. 3, July, 2017 [p-ISSN: 0254-7821, e-ISSN: 2413-7219] 


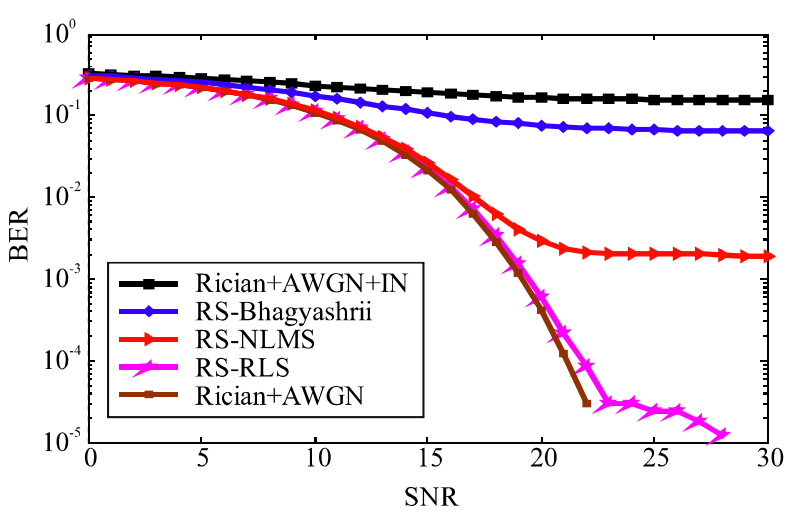

FIG. 14. COMPARISON OF BER FOR PROPOSED HYBRID TECHNIQUESIN RICIAN FADING CHANNEL

fading channel. The performance of our suggested hybrid technique (RS-RLS) outperforms its other variants in suppressing impulsive noise in Rician fading channel.

\section{CONCLUSION}

In this paper, a New hybridtechniquefor impulsive noise cancellation based on combination of RS coding and adaptive filter for OFDM systems is presented. The three variants of adaptive filter family i.e. NLMS, Bhagyashri and RLS algorithm are tested for mitigating impulsive noisefrom received OFDM signal. Better reduction in impulsive noise is achieved by adaptive algorithm's ability to track time variations of signal statistics in non-stationary environment, and enhanced signal reception is attained by employing RS error correction codes. The suggested scheme improves the quality of OFDM signal in terms of low MSE, improved SNR and BER,when compared with recently reported schemes. Moreover, the comparative analysis of proposed hybrid technique is tested in AWGN and Rician fading channel. It is verified from simulation results that hybrid RS-RLS outperforms the other investigated variants in impulsive noise suppression.

\section{FUTURE WORK}

Future work will focus on investigating the performance of state space adaptive algorithms in our hybrid technique and adopting the proposed technique to the MIMO OFDM systems.

\section{ACKNOWLEDGEMENT}

The authors are very thankful to National University of Sciences \& Technology, Rawalpindi, Pakistan, for providing all the necessary facilities to successfully complete this research.

\section{REFERENCES}

[1]

[3]

\begin{abstract}
Al-Naffouri, T.Y., Ahmed, Q., and Giuseppe, C., "Impulsive Noise Estimation and Cancellation in DSL using Orthogonal Clustering”, Proceedings of $20^{\text {th }}$ IEEE International Symposium on Information Theory, pp. 2841-2845, St. Petersburg, Russia, August, 2011.

Ardakani, M., Colavolpe, G., Dostert, K., Ferreira, H.C., Fertonani, D., Swart, T.G., Tonello, A.M., Umehara, D., and Vinck, A.J.H., "Digital Transmission Techniques, in Power Line Communications: Theory and Applications for Narrowband and Broadband Communications over Power Lines”, (Ferreira, H.C., Lampe, L., Newbury, J., and Swart, T.G., [Editors]), John Wiley \& Sons, Ltd, Chichester, UK. [DOI: 10.1002/9780470661291.ch5].
\end{abstract}

Hwang, T., Yang, C., Wu, G., Li, S., and Li, G.Y., "OFDM and its Wireless Applications: A Survey”, IEEE Transactions on Vehicular Technology, Volume 58, No. 4, pp. 1673-1694, May, 2009.

\footnotetext{
Haring, J., and Vinck, H., "OFDM Transmission Corrupted by Impulsive Noise”, Proceedings of International Symposium on Power-Line Communications and its Applications, pp. 5-7, Limerick, Ireland, April 5-7, 2000.
} 
Vaseghi, S.V., "Impulsive Noise, in Advanced Digital Signal Processing and Noise Reduction”, Third Edition, John Wiley \& Sons, Ltd, Chichester, UK, 2005 [DOI: 10.1002/ 0470094966.ch12].

Suraweera, H.A., Chai, C., Shentu, J., and Armstrong, J., “Analysis of Impulse Noise Mitigation Techniques for Digital Television Systems”, Proceedings of $8^{\text {th }}$ International OFDM Workshop, pp. 172-176, Hamburg, September, 2003.

Umatani, T., Ohno, K., and Itami, M., “A Study on Schemes of Reducing Influence of Impulse Noise in OFDM under Multi-Path Channel”, Proceedings of IEEE Conference on Consumer Electronics, Digest of Technical Papers, pp. 119-120, 2010.
[12] Kitamura, T., Ando, H., Ohno, K., and Itami, M., “The Impulsive Noise Reduction Using It's Replica Signal Under Class-A Impulsive Channel”, Proceedings of $15^{\text {th }}$ International Symposium on Wireless Personal Multimedia Communications, pp. 460-464,Taipel, Taiwan, September, 2012.

Kitamura, T., Ohno, K., and Itami, M., "Iterative Impulsive Noise Reduction by Generating its Replica Signal in OFDM Reception”, Proceedings of IEEE Conference on Consumer Electronics, pp. 389-390, Las Vegas, USA, January 9-12, 2011.

[14] Zhidkov, S.V., "Impulsive Noise Suppression in OFDMBased Communication Systems”, IEEE Transactions on Consumer Electronics, Volume 49, No. 4, pp. 944-948, November, 2003.

[15] Al-Mawali, K., Sadik, A.Z., and Hussain, Z.M., "Joint Time-Domain/Frequency-Domain Impulsive Noise Reduction in OFDM-Based Power Line Communications”, Proceedings of $1^{\text {st }}$ IEEE Telecommunication Networks and Applications Conference, pp. 138-142, December 7-10, 2008.

[16] Liu, R., Kung, T.L., and Parhi, K.K., "Impulse Noise Correction in OFDM Systems”, Journal of Signal Processing Systems, Volume 74, No. 2, pp. 245-262, February, 2014.

[17] Farhang-Boroujeny, B., “Adaptive Filters: Theory and Applications”, John Wiley \& Sons, Ltd, Chichester, UK, 2013 [GOI: 10.1002/9781118591352].

[18] Mathew, S., and Murukan, P., "Periodic Impulsive Noise Reduction in OFDM based Power Line Communication”, International Journal on Research in Engineering and Technology, Volume 3, pp. 517-522, May, 2014.

[19] Ahmed, M.A., Jimaa, S.A., and Abualhaol, I.Y., "Performance Enhancements of MIMO-OFDM System using Various Adaptive Receiver Structures”, International Journal of Computer and Information Technology, Volume1, No. 1, pp. 99-106, September, 2012. 
[20] Hakam, A., Aly, N.A., Khalid, M., Jimaa, S., and AlAraji, S., "Impulsive Noise Reduction in MIMO-OFDM Systems using Adaptive Receiver Structures”, Proceedings of $20^{\text {th }}$ IEEE Conference on Electronics, Circuits and Systems, pp. 674-677, Dubai, UAE, December 9-12, 2013.

Hakam, A., Aly, N.A., and Jimaa, S., "Impulsive Noise Mitigation in a MIMO-OFDM Communication System”, Proceedings of $6^{\text {th }}$ IEEE Conference on New Technologies, Mobility and Security, pp. 1-5, Dubai, UAE, March 30-April 2, 2014.

[22] Khedkar, A.R., and Murugan, M.M., "Trained Adaptive Filter based Approach to Mitigate ICI in OFDM System”, Proceedings of International Conference on Pervasive Computing, pp. 1-4, Pune, India, January 8-10, 2015.

[23] Prasad, G., Latchman, H.A., Lee, Y., and Finamore, W.A, “A Comparative Performance Study of LDPC and Turbo codes for Realistic PLC Channels”, Proceedings of $18^{\text {th }}$ IEEE International Symposium on Power Line Communications and its Applications, pp. 202-207,Glasgow, UK, 2014

[24] Praveenkumar, P., Amirtharajan, R., Thenmozhi, K., and Rayappan, J.B.B., "Regulated OFDM Role of ECC and ANN: A Review", Journal of Applied Sciences, Volume12, No. 4, pp. 301-314, February, 2012.

Praveenkumar, P., Thenmozhi, K., Rayappan, J.B.B., and Amirtharajan, R., "Reversible Steganography on OFDM Channel-a Role of RS Coding”, Journal of Information Technology, Volume 13, No. 12, pp. 2052-2056, June, 2013.

[26] Hu, X., Chen, Z., and Yin, F., "Impulsive Noise Cancellation for MIMO Power Line Communications”, Journal of Communications, Volume 9, No. 3, pp. 241-247, March, 2014
Mirza, A., Kabir, S.M., and Sheikh, S.A., "Reduction of Impulsive Noise in OFDM Systems using a Hybrid Method”, Proceedings of $6^{\text {th }}$ International Conference on Signal and Information Processing, Bangkok, Thailand , July 6-7, 2015.

Jia, J., and Meng, J., “A Dual Protection Scheme for Impulsive Noise Suppression in OFDM Systems”, International Journal of Electronics and Communications, Volume 68, No. 1, pp. 51-58, January, 2014.

Jia, J., and Meng, J., “A Novel Approach for Impulsive Noise Mitigation in ZigBee Communication System”, Proceedings of IEEE Global Information Infrastructure and Networking Symposium, pp. 1-3, September 15-19, 2014.

Gulati, K., Evans, B.L., Andrews, J.G., and Tinsley, K.R., "Statistics of Co-Channel Interference in a Field of Poisson and Poisson-Poisson Clustered Interferers", IEEE Transactions on Signal Processing, Volume 58, No. 12, pp. 6207-6222, December, 2010.

[31] Middleton, D., "Non-Gaussian Noise Models in Signal Processing for Telecommunications: New Methods and Results for Class A and Class B Noise Models”, IEEE Transactions on Information Theory, Volume 45, No. 4, pp. 1129-1149, May, 1999.

[32] Tsihrintzis, G.A., and Nikias, C. L., "Fast Estimation of the Parameters of Alpha-Stable Impulsive Interference”, IEEE Transactions on Signal Processing, Volume 44, No. 6, pp. 1492-1503, June, 1996.

[33] Yang, P., Guan, Y. L., Liu, X. B., and Wang, W. W., "Detection of Single Carrier Transmission in Frequency Selective Fading Channels with Symmetric Alpha-Stable Noise”, Proceedings of IEEE Military Communications Conference, pp. 1114-1119, October, 2015. 
[34] Zhang, X., Viswanathan, V.R., and Unno, T., "US Patent Application No. 12/167,026”, 2008.

[35] Sklar, B., "Digital Communications: Fundamentals and Applications”, Prentice Hall, Inc. Upper Saddle River, NJ, USA, 2001.
Torío, P., Sánchez, M.G., and Cuiñas, Í., “An Algorithm to Simulate Impulsive Noise", Proceedings of $19^{\text {th }}$ International Conference on Software, Telecommunications and Computer Networks, pp.1-4, Split, Croatia, September 15-17, 2011.

[37] Rupp, M., "Adaptive Filters: Stable but Divergent”, EURASIP Journal on Advances in Signal Processing, Volume 1, pp. 1-15, 2015. 